\title{
Map of the terminal moraine of the Werenskioldbreen glacier (South-West Spitsbergen) from 2015
}

\author{
Laura Downar-Zapolska ${ }^{1}$, and Tadeusz Głowacki ${ }^{1, *}$ \\ ${ }^{1}$ Wroclaw University of Science and Technology, Faculty of Geoengineering, Mining and Geology, \\ 27 Wyb. Wyspianskiego St., 50-370 Wroclaw, Poland
}

\begin{abstract}
The first direct field measurement of the entire terminal moraine of the Werenskioldbreen glacier on Spitsbergen took place at the end of July and the beginning of August 2015. The results of the measurements were the basis for the development of the large-scale terminal moraine map. The article presents the stages of map creation and editing based on measurement points established by the GNSS method. The map editing required knowledge of the morphologically complex terrain. Key documentation was field notes and documentary photographs, enabling the cartographic interpretation of the varied topographic features of the terrain's surface. Based on the documentation, the water bodies on the moraine were located, the outline of the structure and the boundary points were executed and the latter were excluded from the triangulation process. The glacial river was also excluded from triangulation, which allowed a DTM to be developed. An important step in point cloud mapping was to generate a topologically correct digital elevation model of satisfactory accuracy. On the basis of the DTM, contour lines were generated showing the topographic features of the terrain's surface. The printable resultant map's scale is 1: 5000; it is in the UTM coordinate system, in the $33 \mathrm{X}$ zone. Complementing the content of the map, a grid of geographic coordinates, a kilometer grid, and map key descriptions were added.
\end{abstract}

\section{Introduction}

Global climate changes are the most visible in polar regions. Surface changes are noticeable with the naked eye; maps as cartographic studies help one to document the changes that have occurred on the surface. Most studies in the polar regions focus on assessing climate changes and the impact of the changes on the environment. The interest in the polar regions, as well as greater accessibility to them, make them be a growing topic of debate about Earth and the environment. Polish scholars engaged in polar studies primarily focus on Spitsbergen [1], where international projects are implemented, including workshops and conferences. Research within the scope of various scientific disciplines is conducted in this

"Corresponding author: tadeusz.glowacki@pwr.edu.pl 
area. There are 6 Polish polar bases in the Svalbard archipelago, which are supervised by scientific centers such as Maria Curie-Skłodowska University in Lublin, Institute of Geophysics of the Polish Academy of Sciences, Nicolaus Copernicus University in Torun, Adam Mickiewicz University in Poznań, Jagiellonian University and Wroclaw University [2]. With the growing interest in polar subjects, and the possibilities of using geodetic methods in the polar regions, cartographic studies began to appear. Analogue topographic maps were once the only source of information on topographic features of the terrain. By analyzing the collected material, researchers have been able to see changes in both relief, location of terminus of the selected glacier, or height changes in the glacier area $[3,4]$. New technologies and methods of data collection enable the development of polar research and the resulting possibilities. Currently, the choice of technology itself depends on economic and logistic aspects. Today, satellite technology is the leading one. The GNSS measurement method is unrivalled in small areas where measurement has to be done with great accuracy, while in case of large areas, they are mapped by means of photogrammetric and remote sensing methods. Software and hardware have contributed to the development and increase in a number of cartographic documents concerning polar areas. The development of measurement techniques and the possibility of obtaining accurate data have led to an increase in the number of polar regions that are considered both interesting and dangerous. In addition, geodetic measurements are part of the non-invasive polar research without disturbing or interfering with the environment.

\section{Scope of the study}

The entire area of Svalbard is protected, so scientists must comply with the rules imposed by the Governor of the archipelago. Measurements were made on Spitsbergen - the largest island of the Svalbard archipelago between $74^{\circ}$ and $81^{\circ} \mathrm{N}$ and $10^{\circ}$ and $35^{\circ} \mathrm{E}$. In global terms it is approx. $800 \mathrm{~km}$ north of Norway and approx. $1100 \mathrm{~km}$ south of the North Pole [2]. The measurement facility is located in the southern part of Spitsbergen, in Wedel Jarlsberg Land, in the Hornsund Bay. The measurement area is shown in Fig.1a. On fig.1b is shown the Werenskioldbreen glacier $[5,6]$ on TopoSvalbard web page.
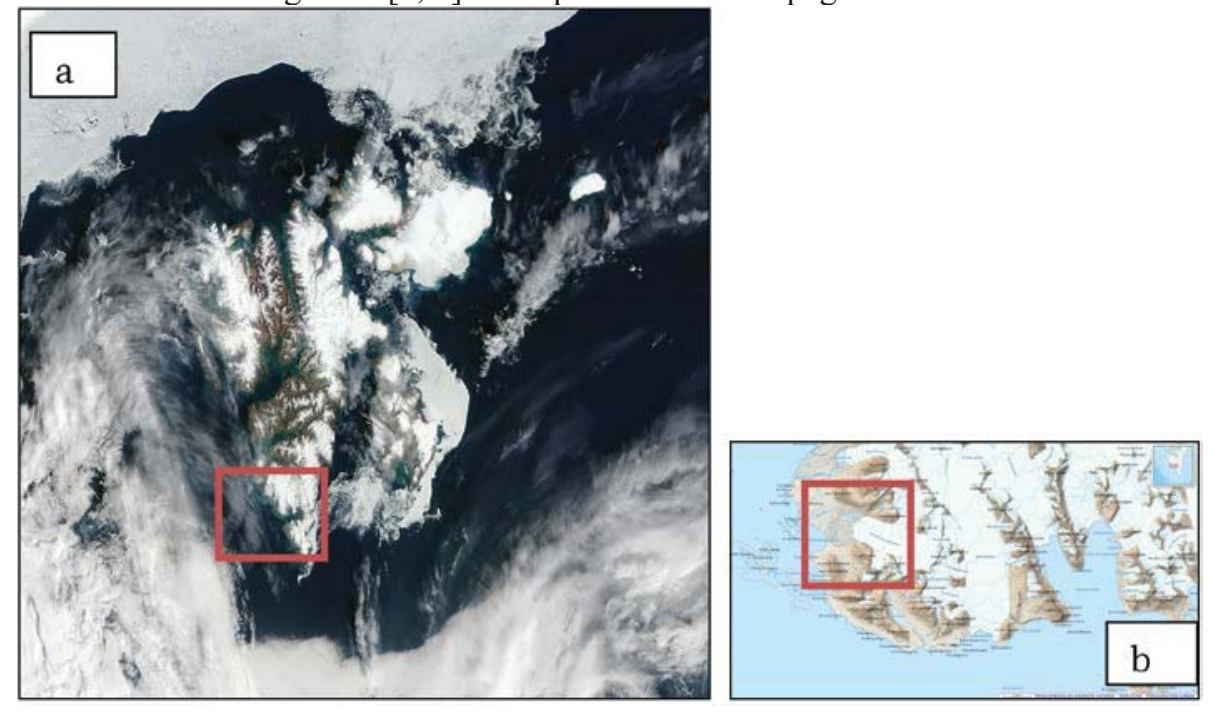

Fig. 1. a) Svalbard - NASA photo from August 8th, 2015 with measurement area marked [7]; b)

Wedel Jarlsberg Land with the area of research [8]. 


\section{Svalbard maps}

\subsection{Historical background}

The first work on Svalbard's mapping began more than 100 years ago. Then participants in the Swedish-Russian expedition of 1899-1902 conducted measurements to determine the shape and size of Earth. They measured the length of the meridian arc on the east coast of Spitsbergen. During this period, the first cartographic documents were drawn that met the criteria of carto metrics [9]. Historical maps created at the turn of the 17th century depict the development of cartography of the northern regions. The first document dates back to 1596. Willem Barents, a Dutch cartographer, during his third expedition, developed a map showing the first outline of Spitsbergen coast. Historical studies are characterized by the fact that they were not based on any measurements but on the observations of people engaged in the expansion of the polar regions. Graphic forms such as animals or ships were designed to fill in empty spaces that were not discovered.

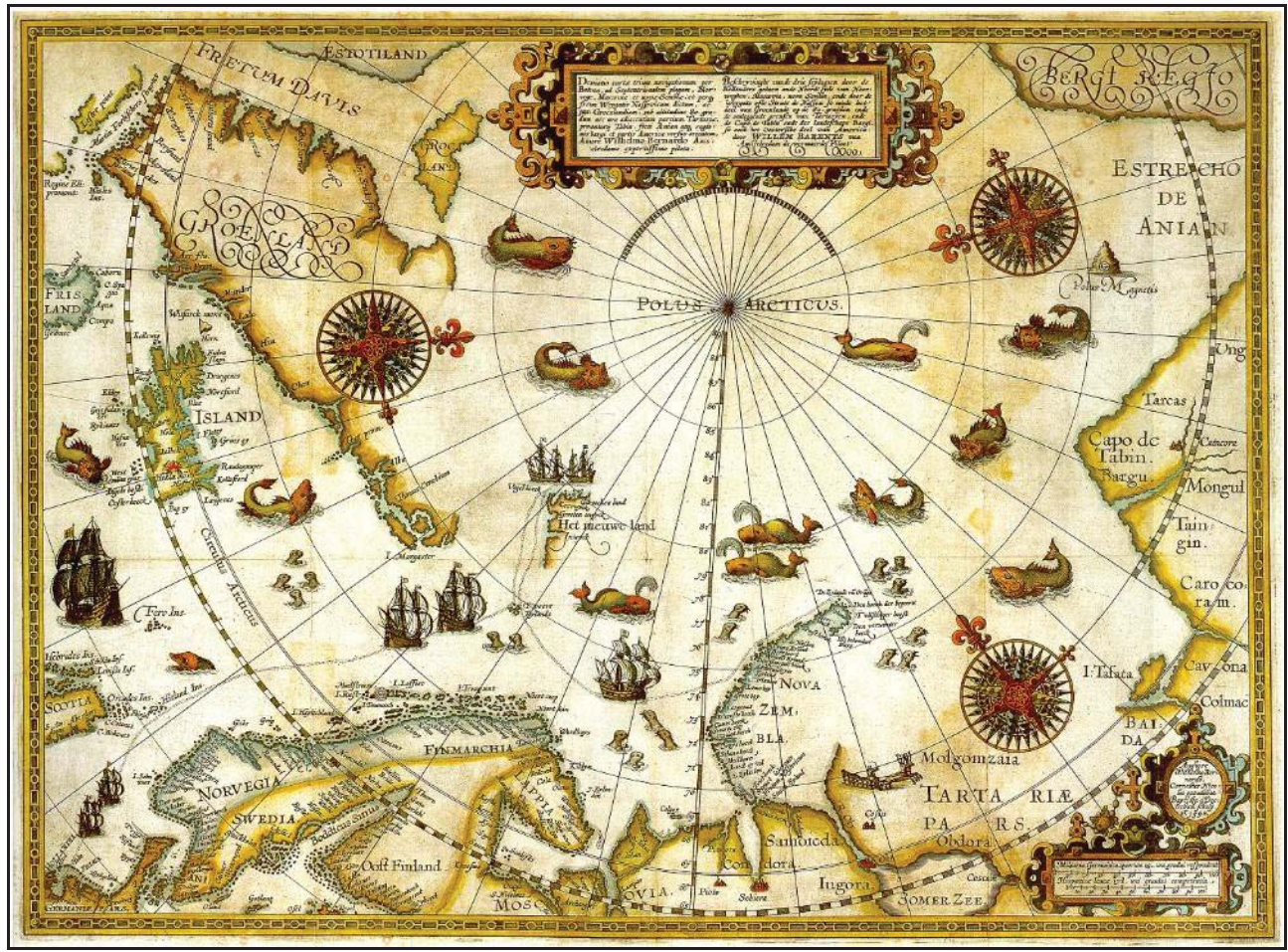

Fig. 2. First cartographic study with the Spitsbergen shores - Willem Barents, 1599 [10].

Fishing, whaling and hunting contributed to the development of cartography of the Spitsbergen area. However, until the development of Svalbard's first cartometric map, other maps were just the results of subjective observations, so many discrepancies in the Spitsbergen coastline between the studies can be observed. The 20th century was a time of scientific research and numerous expeditions. Thanks to technology and measurement possibilities, the first world's most famous scientists arrived in the Arctic. The main subjects were geology and glaciology. Numerous thematic maps - geological and geological - of Spitsbergen were first developed. The researchers from England, Sweden, Norway, Germany and Austria led the way in these expeditions [10]. 
After the First World War, the development of measuring and cartographic technologies took place. The demand in the extraction industries for the cartographic studies of the selected area increased. In 1936 Svalbard mapping started using photogrammetric methods. The area of measurement covered 40,000 km, 2. 3800 photos were taken then. Photos were taken on a scale from 1:30 000 to 1:50 000. After the Second World War, they were developed with a working scale of 1:50 000, and published on a scale of 1: 100,000 in the Gauss-Krüger transverse cylindrical projection. After that mapping, the maps were used as base maps for a long time [9].

\subsection{Contemporary cartographic works}

Modern technology, which develops at a rapid pace, enables both precise measurements and quick results development and visualization. Thanks to topographic maps and aerial photographs, numerous scientific research and studies on glaciers of various types have been made, and the glaciers cover almost $60 \%$ of Svalbard. With the GNSS geodetic surveying technology, the speed of glacier movement is currently being monitored, and then the position of their snouts is mapped onto the basic map.

There are maps of each region of Svalbard available. Topographic maps were scaled as follows: 1: 500,000, 1: 250,000, 1: 100,000. 1: 100,000 scale maps are a series of 62 sheets representing the entire archipelago divided into parts. Most of the sheets were made in the WGS-84 reference system. The exceptions are G7 and H7 sheets - they were made in ED50 system (reference: Hayford ellipsoid). The assumed contour interval of these maps is $50 \mathrm{~m}$. The sheets were developed on the basis of photogrammetric photographs made in 1990. The exception is sheet 6 because it was also developed on the basis of the flight pass over this area made in 2009. The advantage of photogrammetric methods in Svalbard is undoubtedly the fact that a large area can be measured in a short space of time. In addition, the measurement is also conducted in hard-to-reach areas. In their works, Małgorzata Blaszczyk and Leszek Kolondra [4, 11] claim that photogrammetric methods are among the best methods of obtaining data in polar areas. An orthophotomap is often used in glaciated areas. Its greatest advantage is that the data for its development can be obtained quickly and the measurement covers a large area of land, even hard-to-reach one. The number of measurement points is very high, and thus the relief is well represented on the map. What is more, the method enables further work with data based on the generated digital terrain model. A DTM is a model that is a set of information about the topographic features of the land in the form of points with specific XYZ coordinates. In order to get an accurate orthophotomap it is important to make sure that a DTM is of the highest quality. Therefore, manual point height correction should be performed if necessary. The DTM on this orthophotomap was presented with a grid of squares of $20 \mathrm{~m}$ side. In order to maintain a clear representation of the field situation, additional points and break lines were added. Currently, software and hardware make it possible for cartographers to produce accurate maps, and most editorial operations allow for automatic generation of structures that fall into the map content. An additional advantage of an orthophotomap is that it is not interpreted by the editor [6].

The main administrator of the Svalbard maps and their publisher is the Norwegian Polar Institute (Norsk Polarinstitutt) in Tromso (Norway). They provide both printed and digital maps.

Norsk Polarinstitutt provides digital maps via the following websites:

a) TopoSvalbard - a topographic map portal developed by the Norwegian Polar Institute, where one can see the details of the selected area and view aerial photographs. The user has the possibility of reading coordinates (however, their accuracy, which is represented on the map, is not useful for detailed geodetic 
surveys), search for a town name, measure distance and area. This portal also provides a 3D view.

b) Svalbardkartet - Svalbard interactive map collection. It is possible to include thematic layers on the environment, glaciers and hunting grounds [12].

\subsection{Polish cartographic documents concerning Spitsbergen}

Polish scientists have contributed to the development of scientific research on Spitsbergen, including the development of cartographic studies. The substantive contribution to Polish and world's polar research is appreciated worldwide. The first Polish scientific expedition was organized in 1934 by Stanisław Siedlecki, geologist. The study area was the southwestern part of Torell Land. The main premise of this expedition was to map the previously unmeasured area using the triangulation method and photogrammetric record. The result of the study was a 1:50 000 map, issued by the Polish Military Geographical Institute in 1936. The map was bicolour, and the contour interval was $50 \mathrm{~m}$. Its authors were Antoni Zawadzki and Sylweriusz Zagrajski.

Cartographic documents are produced for research purposes. The increase in the number of maps covering the Hornsund area was accompanied by the development of research facilities, i.e. the construction of polar stations. The main station in Wedel Jarlsberg Land is Stanisław Siedlecki Polish Polar Station managed by the Institute of Geophysics of the Polish Academy of Science in Warsaw. Interest in Werenskiold glacier and research conducted in its vicinity contributed to the establishment of Stanisław Baranowski Polar Station of Wroclaw University in 1971. The possibility of using the station by Polish scientists made the majority of Hornsund area be mapped by Poles. Polish research teams have published a number of cartographic documents covering the areas of Svalbard. Typical map scales range from 1: 2000 to 1: 100000.

The following maps are produced in the polar areas [13]:
a) topographic,
b) geological,
c) glaciological,
d) geomorphological,
e) orthophotomaps,
f) Other (bathymetric, hipsometric and DTM).

In the group of topographic maps, the documents in scales 1:20000 and 1:25 000 are prevailing. Large-scale maps were formerly developed using analogue measurement methods. They covered the relief of the glacier area (e.g. Werenskiold Glacier) and the marginal zones. Topographic middle-scale maps are basic maps for other documents and are used for comparisons of changes in relief and glacial surface height in time.

The interest in Werenskiold glacier came in 1957 when the 3rd International Geophysical Year started. The expeditions were attended by specialists from the Topographic Military Service of Polish Army. One of the participants of these expeditions was Lieutenant Colonel Cezary Lipert, who carried out measurements to produce a Werenskiold glacier map [14]. The measurement method was terrestrial "terrophoto" photograps that were made by the Zeiss-Jena theodolite. C. Liper and M Bałdyga were responsible for autogrammetric processing. The result of the study was a map developed by T. Naumienko in two sheets: Werenskioldbreen Glacier - terminus zone, Werenskioldbreen Glacier - central zone. The map was produced on a scale of 1: 5,000. The applied contour interval was $1.25 \mathrm{~m}$. The Gauss-Krüger mapping for $\lambda=15^{\circ}$ was adopted. Due to the method of measurement of terrestrial photographs, the map was made in local system, with the starting point of $x=8500$ and $y=5400$. In 1960 Jan Szupryczyński used a topographic map developed by T. Naumienko as a basemap for geomorphological mapping of marginal 
zone forms while conducting geomorphological surveys in the forefield of the Werenskiold Glacier $[15,16]$. The scientist evaluated the map as the most detailed representation of the Hornsund area. Therefore, he decided to conduct research in this area due to the fact that he had the accurate cartographic material.

The next development was an orthophotomap. As a result of cooperation between Leszek Kolondra, and scientists from Norsk Polarinstitutt in Tromso, 17 images on a scale of 1:50 000 were used to produce a 1:25 000 orthophotomap (Fig. 3) [17]. It was developed in a standard coordinate system used in Svalbard - UTM - and the adopted reference ellipsoid was WGS-84. The development methods of the orthophotomap of Werenskiold glacier and its surroundings had their limitations. It was necessary to have accurate coordinates of the photo control points in order to correctly carry out this development. These points had to be high-precision, so they had to be measured by direct methods. GNSS receivers are currently used for this purpose. The identification of photo control points is difficult [11]. The glacier surface often does not have any characteristic points. In addition, varied relief, characterized by considerable height differences of the land, creates shadows that are difficult to correct.

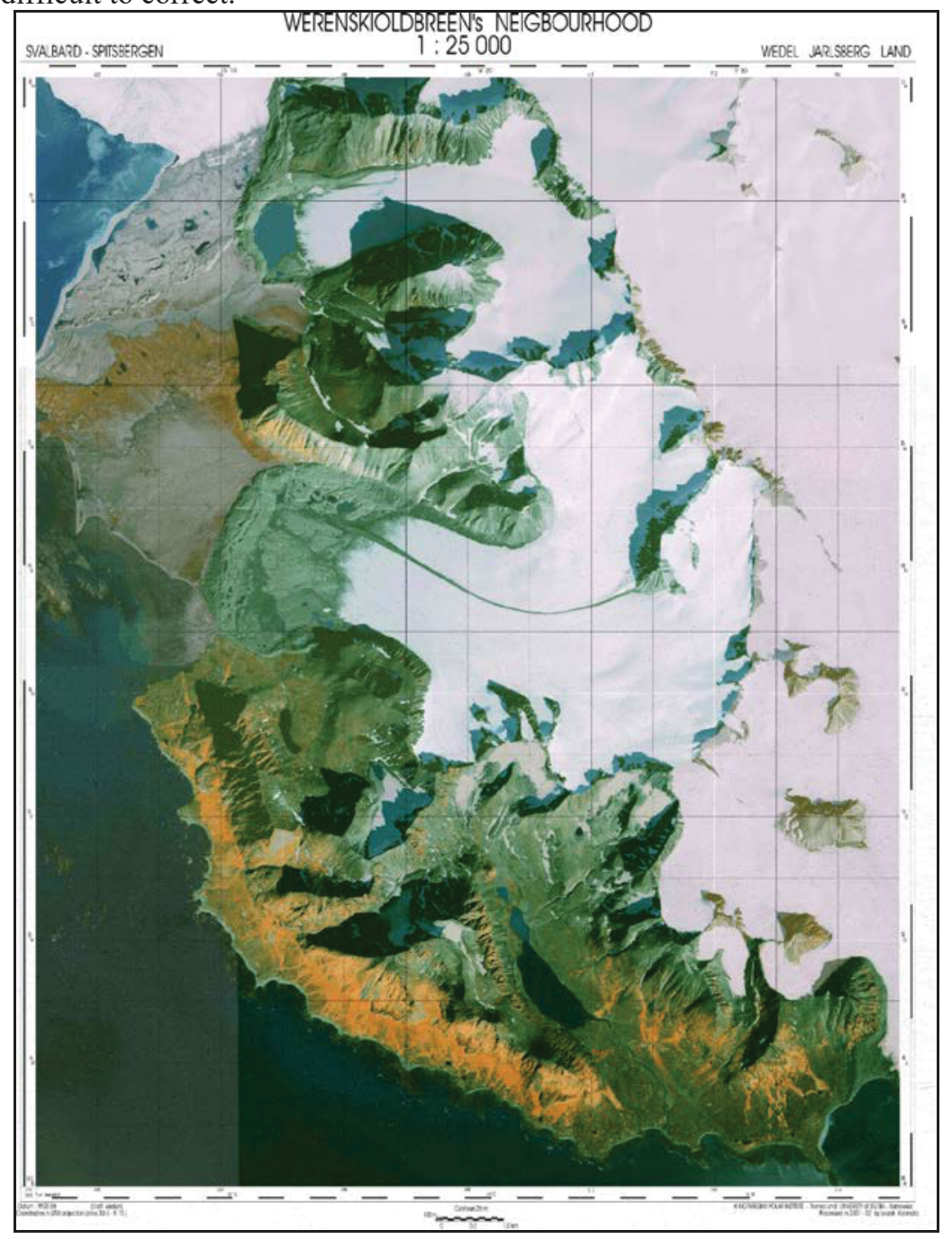

Fig. 3. Orthophotomap "Werenskioldbreen's neighborhood" [17]. 


\section{Method of data collection for -producing a map of the terminal moraine of the Werenskioldbreen glacier}

Many of the published maps are based on photogrammetric methods, based on terrestrial imagery processing or photogrammetric record. On the other hand, scientists from Wroclaw University of Technology within the framework of the III Polar Expedition in 2015 have measured the entire terminal moraine of the Werenskioldbreen glacier in south-west Spitsbergen. The measurement was conducted from 5 July to 16 August 2015. Measurements were made within the scope of the project "Geodetic measurements of the Werenskioldbreen glacier (South Spitsbergen)", which was registered in the database of The Research in Svalbard (RIS) with number 10257 [18]. Field work enabled GNSS receivers to obtain data using the FastStatic method. Three GNSS receivers were used to measure points. The aim of the study is to present the terminal moraine of the Werenskiold Glacier in the form of a topographic map of 1: 5000 scale. The map was made on the basis of the coordinates of postprocessing measurement points in reference to the nearest EUREF reference stations: Ny-Alesund (NYAL) and Hornsund (ASTR). A total of 20721 station poles were measured, which were characteristic features of the very varied relief. Measurement sessions for 1 point lasted 31". The coordinates of the points were calculated in the UTM system (33X zone) and in the WGS-84 mapping. The average accuracy of the location of the points in the horizontal plane falls within 5 and $25 \mathrm{~cm}$ and in the vertical plane it is within 40 and $60 \mathrm{~cm}$. Because of the time limitation, no field sketches were made, only field notes were used to identify point groups and point numbering sequences.

\section{Results}

\subsection{Map editing}

Editing the content of the map started with water bodies. The lakes were easy to identify because before the measurement it was assumed that station poles at the edges of the water body were measured one by one, at the water surface. So, the presence of the lake was indicated by consecutive point numbers and an empty spot in the cloud of points. In the case of ambiguity in the interpretation of selected measurement areas, satellite imagery available on the Norsk Polarinstitutt website [19] was used (Fig.4). The pictures clearly show large lakes on the moraine, and the comparison of the shape and location with respect to other structures allowed for unambiguous identification of lakes as enclosed areas. (comparison of Fig. 4a and Fig. 4b). Figure 5 shows a fragment of a vector map with the lake inserted into a point cloud. 

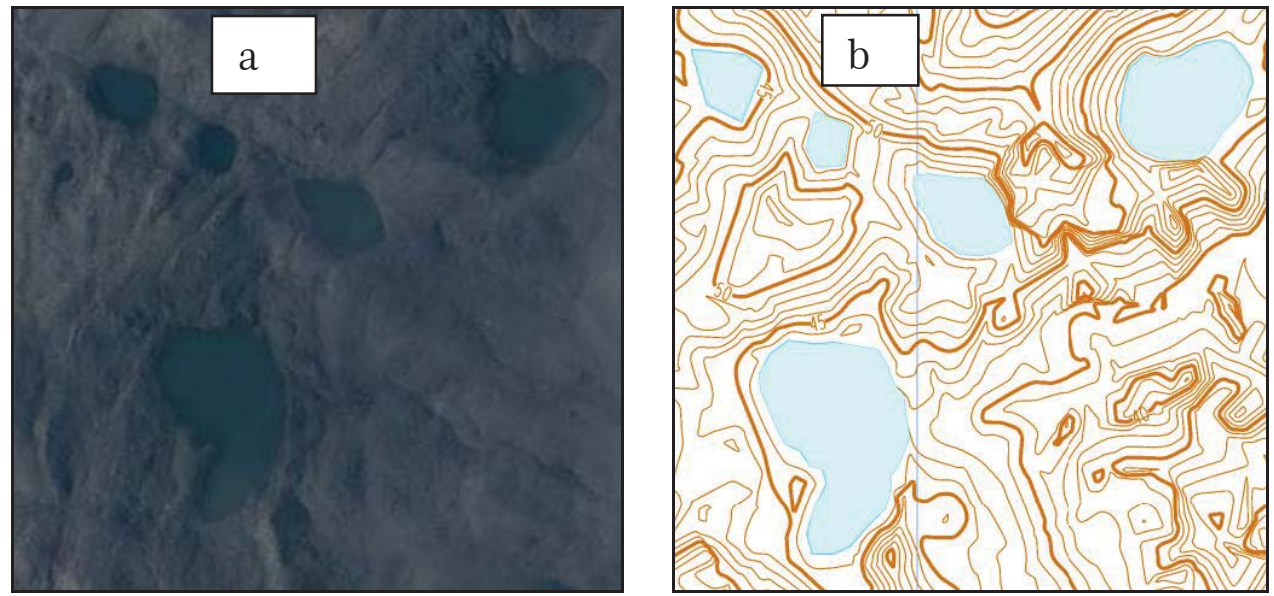

Fig. 4. a) Fragment of the satellite image - lakes on the moraine [19]; b) Fragment of the developed map - lakes located on the moraine.

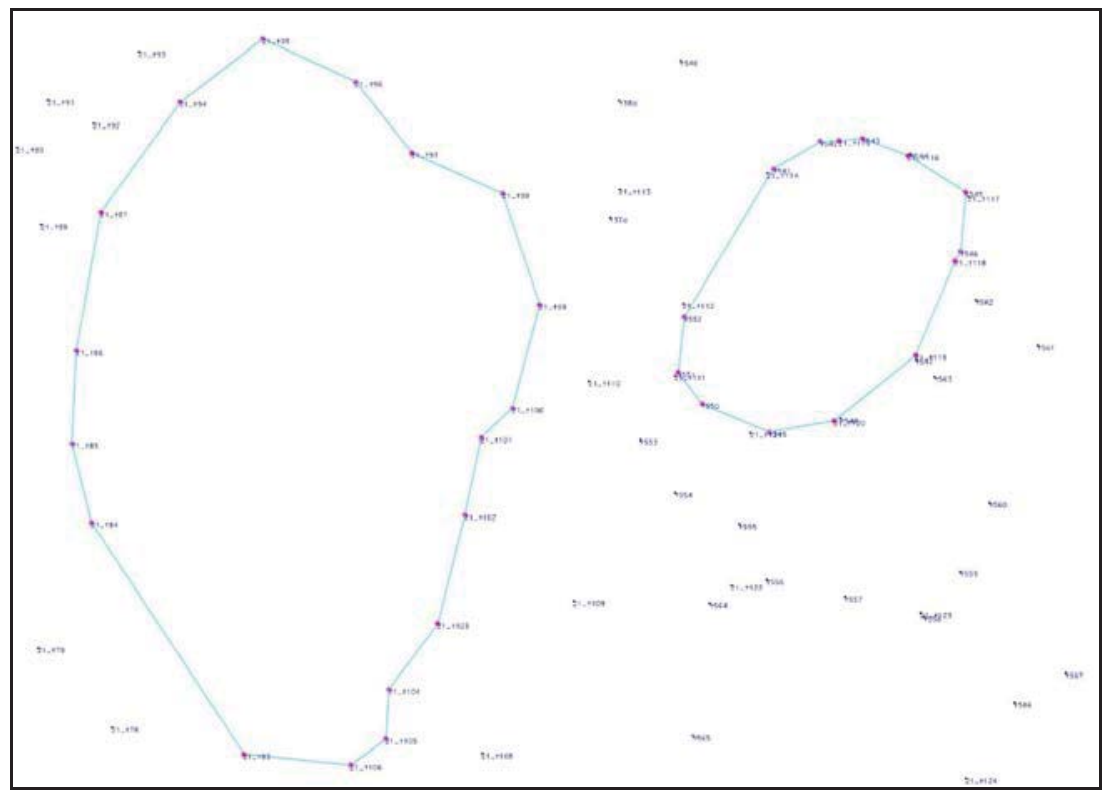

Fig. 5. Identification of water bodies.

The next stage was the development of the glacial river bank line. The basis for identification was, like with the water bodies, the numbering of measurement points, and the information recorded in the field notebook. Points of the riverbank were joined by a line that formed the outline. In addition, the points of the riverbank line limited the measurement area from the east. The limitation from the western, northern and southern sides was the foot of the glacier's terminal moraine escarpment. The measurement ended at the foot of the moraine escarpment. In order to indicate the flattening, apart from the escarpment, there were still 1-2 additional points located along the entire south, west and north sides.

The photographic documentation was a valuable source of information when identifying water bodies. Approximately 500 images of terminal moraine along with the surrounding area were taken. Thanks to them, it was possible to determine the shape of the lakes, the 
bankline of the glacial river, the location of the hills, peaks, saddles, valleys, ridges, skeletal lines, break lines like cliffs and slopes, characteristic points and other terrain forms, as well as their position relative to each other. An example of a photo is shown in Figure 6.

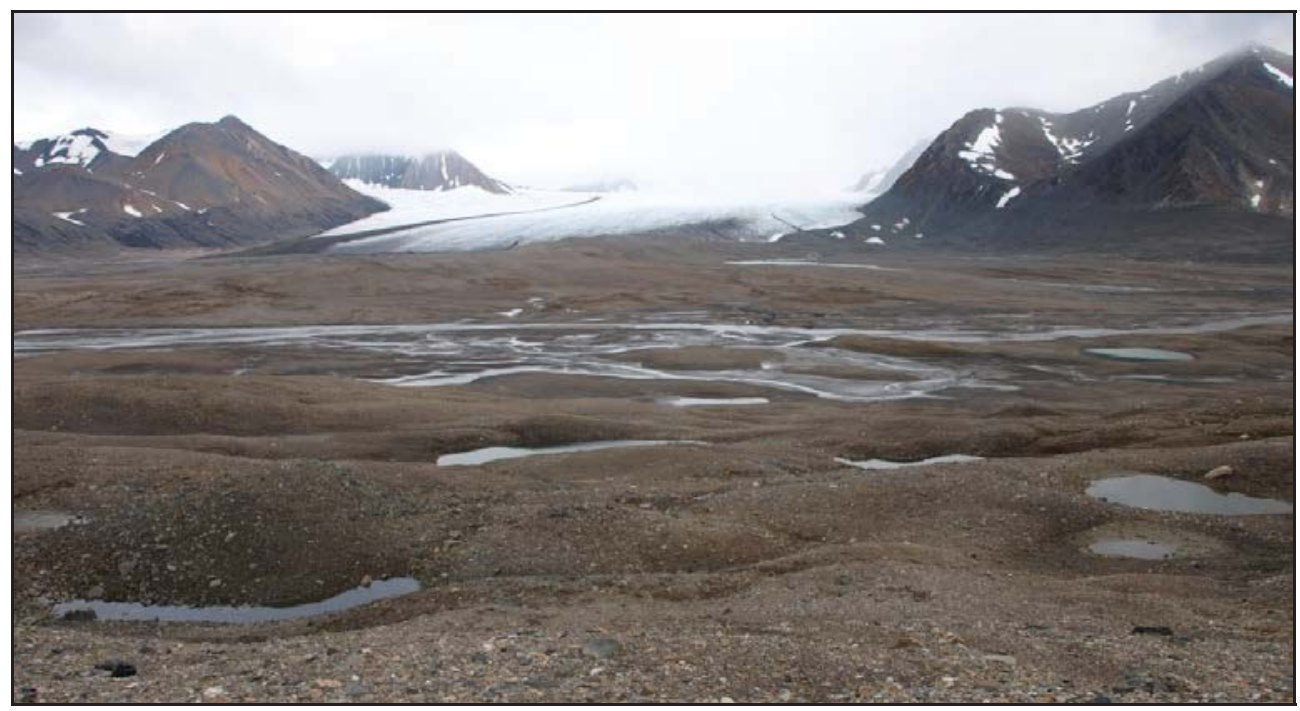

Fig. 6. Photo of the terminal moraine's fragment with the lakes and glacier river in the central part of the photo (photo. T.Głowacki, 8/8/2015).

\subsection{Digital Terrain Model}

Digital Terrain Model is a set of data in a form of points of XYZ coordinates, which, based on interpolation algorithms, recreates the shape of the terrain surface. The boundaries of DTM were determined by the measurement area described in the preceding paragraph.

The next stage of the development was the triangulation (applying a grid of triangles) between all measured points for the whole area. The lakes and the glacial river were excluded from the calculations, and the defined characteristic points were included in the structure. As a result of the automatic operation of connecting the nearest neighbours, a digital terrain model in a form of a triangulated irregular network (TIN) was created according to the rule of nearest-neighbour connection (Fig. 7). The model was saved in a universal .dtm format. The vertices of the generated triangles were measurement points directly measured. This model was the working version, because each model should be subjected to control. Initial verification of the resulting model allowed for the elimination of gross errors and errors resulting from measurement imperfections. The points that stood out from the model were deleted. Another surface triangulation process no longer contained points that were significantly different from the surface model. In total, about 110 points were removed which definitely did not match the generated model. 


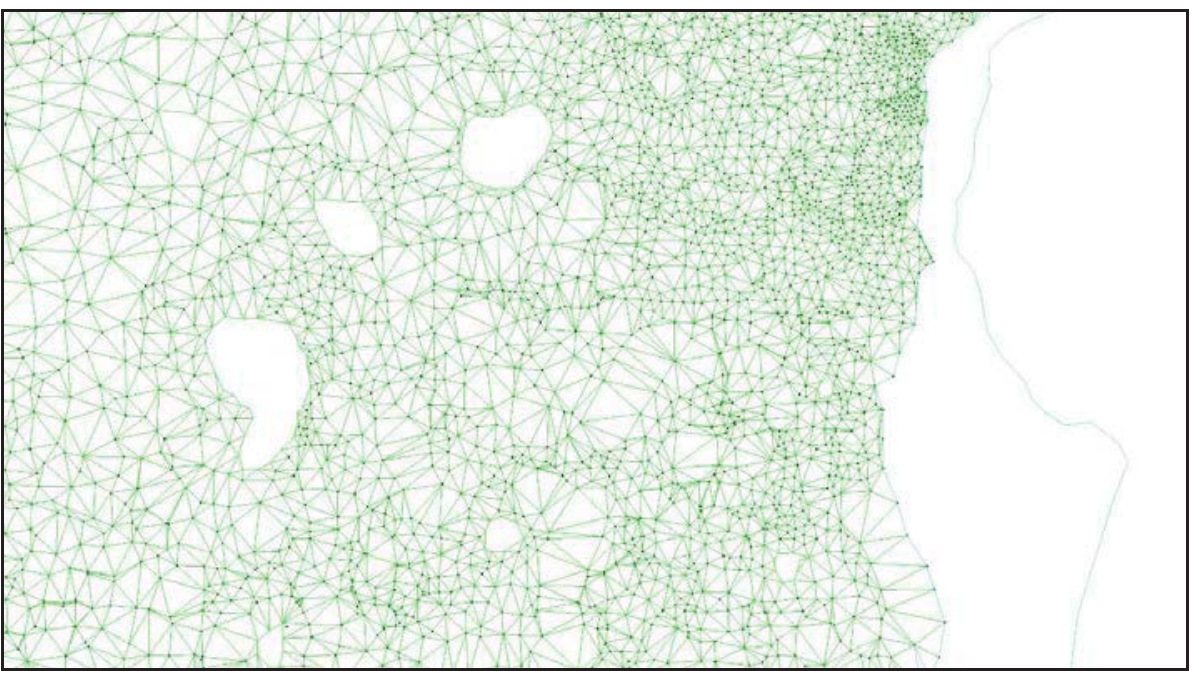

Fig. 7. Fragment of the generated Digital Terrain Model in TIN form - top view.

\subsection{Contour lines}

Contour lines are lines joining points of the same height on the map at a reference level. They depict the topographic surface and enable one to control the previously developed DTM.

In this study, contour lines of $1 \mathrm{~m}$ basic interval were generated in order to eliminate the wrong heights that were applied to the measuring points model. Contour lines were automatically generated using the linear method embedded into the functionality of the application used. The main contour lines were every $5 \mathrm{~m}$, and the auxiliary contour lines were every $1 \mathrm{~m}$. Along with the interpolation of the contour lines, the descriptions constituting the elevation features of the contour lines and the labels in the characteristic points were generated. The result of automatic generation is shown in Fig. 8.

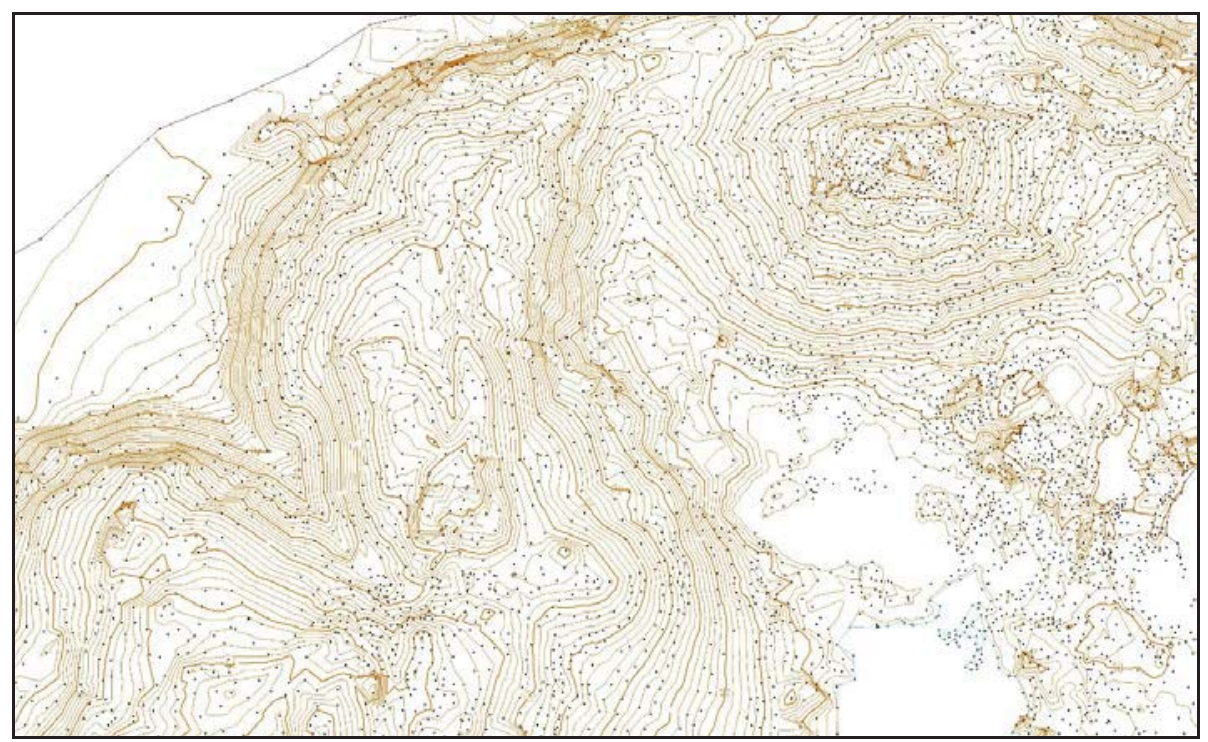

Fig. 8 The result of generating a drawing of contour lines of $1 \mathrm{~m}$ interval. 
After drawing out the contour lines, it turned out that among the set of points there were those that deviated from the average height values occurring in a given measuring area. An example of the wrong contour lines is shown in Figures 9a and 9b. The error could be caused by measurement inaccuracies, such as a temporary loss of GPS signal in an area with a covered horizon. Comparison of moraine form drawn out on the basis of contour lines with satellite imagery and documentation photographs of the moraine made it possible to definitely exclude wrong measurement points. Analysis of the accuracy of measurement of vectors to the reference points confirmed the validity of the decisions taken. Throughout the project, the analysis of contour lines and satellite imagery allowed for the location of about 260 outlying points that were removed from the DTM.
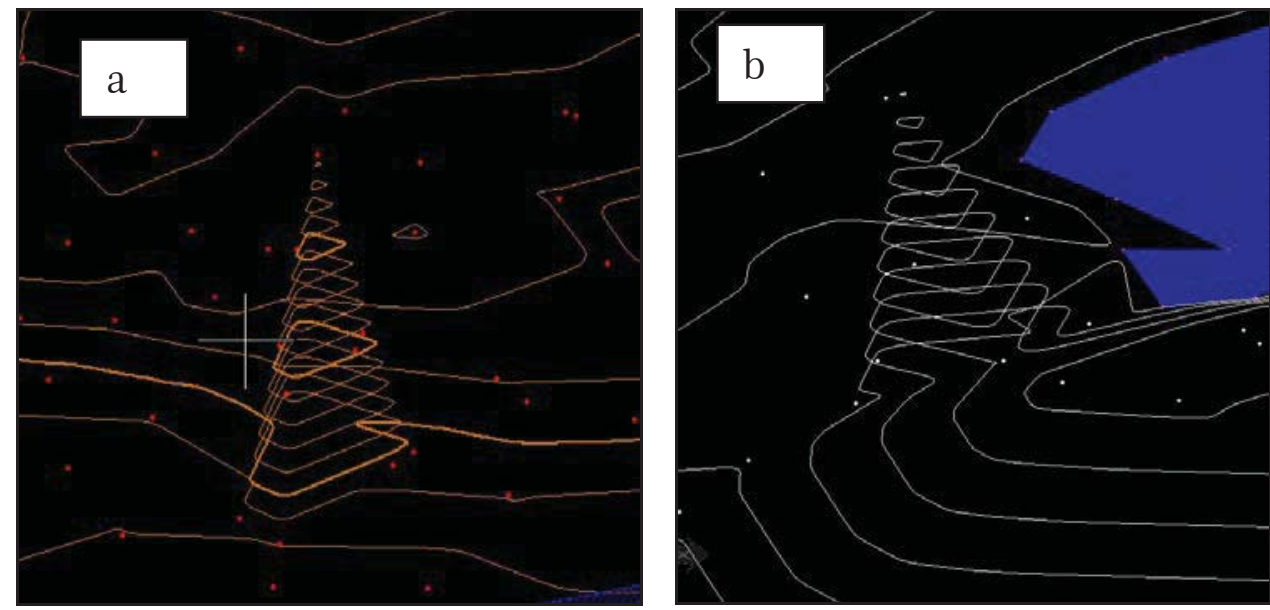

Fig. 9. a) An example of wrongly generated contour lines; b) An example of erroneously generated contour lines.

The mutual arrangement of the contour lines allowed one to re-check the layout of the land. New, smaller lakes were observed in land depressions. The boundary points had another numbering on the map. Another comparison with satellite imagery and field photographs confirmed the correctness of the procedure. Unfortunately, some of the water bodies identified on the moraine could not be found in the photographs, which indicates the surface changes in the layout of the glacier's terminal moraine. After total correction, approximately 355 points $(1.7 \%)$ were removed from the initial set of 21,000 points. A new digital terrain model was then generated from the remaining set of points. On the basis of the moraine model, the contour lines of $1 \mathrm{~m}$ basic interval and thickened contour lines every $5 \mathrm{~m}$ were automatically drawn out.

\subsection{Editing map content}

The process of map development and editing requires the editor to be familiar with the specifics of the area as well as the individual approach to the topic of the development. Although there is currently access to technology supporting cartographic developments and most operations can be done automatically, the limitations of the automation implemented in the programs must be taken into account, and thus the need to manually correct the resulting map.

After developing the digital terrain model, a map was to be made more readable. The first stage of editing the content of the map was to analyze the course of the contour lines. As a result of interpolation, contour lines were generated with "sharp" contours, contour 
lines in contact or looping. Such a situation may be a consequence of automatic interpolation and smoothing algorithms, which do not work in a complex and varied terrain, generating a lot of errors. The course of the contour line on the map should be smooth. In the first close-up, not all contour shapes were smoothed out. It was necessary to carry out a manual correction of this type of contour lines.

The elevation values of the basic contour lines on the map were added automatically. Only the font, size, and repetition distance of the contour feature in the same line were specified. In areas with a large fall of the land, not only the value contour but also the nearest auxiliary contours are interrupted (Fig.10). Therefore, it was necessary to close the auxiliary contour lines, and in case of difficulties related to the size of the font, it was also necessary to move the inscription to another place on the map.

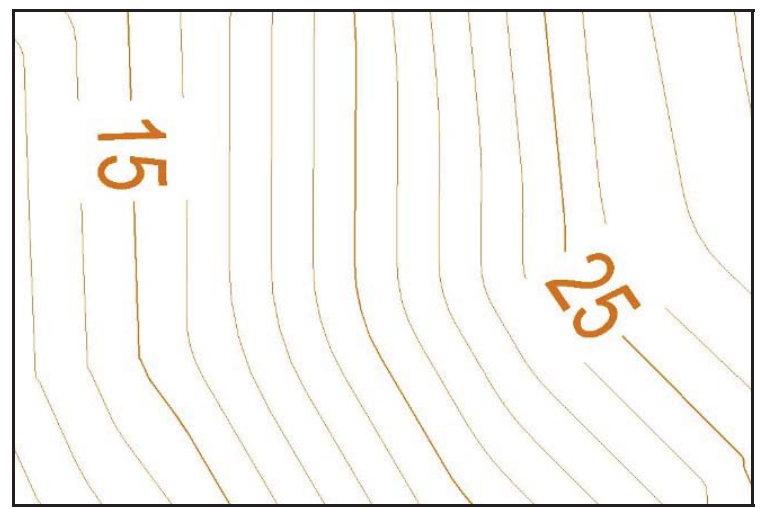

Fig. 10. An example of interrupting neighbouring contour lines in the automatic addition of a height feature.

In addition, defining the distance after which the contours are broken again causes the inscriptions to be inserted into the wrong places, limiting the readability of the map significantly. In such situations, during the editing and making the map more readable the height features were shifted to the most appropriate locations, simultaneously describing the map content and character of the terrain.

After editing structures on the map, two grids were manually drawn in the form of a box: the first kilometer one referring to the UTM coordinate system in zone $33 \mathrm{X}$ and the geographic one with latitude and longitude. Lines separating minutes were added to the frame. Longitudes and latitudes on the box were converted on the basis of the corner points of the frame.

\subsection{Content outside the frame and map printout}

Content outside the frame is an integral part of every map. It contains important information such as title, scale, development information (measurement date, measurement method), coordinate system used and mapping, legend and additional information.

Cartographic development was entitled "Terminal Moraine - South Spitsbergen". 1: 5,000 scale map was developed for printout. Information was included below the content of the map along with a linear scale. The project adopted the UTM coordinate system, zone $33 \mathrm{X}$, binding for the whole Svalbard. The content outside the frame contains important information about the method of measurement and the date of fieldwork. In addition, the names of the people performing the measurement and the map editor are listed. Due to the 
layout of the prepared map, it was possible to place the legend in a vacant part of the map within the frame.

Because of the large area and elongated shape of the moraine, the map was printed on an A1 format sheet. The vector map was converted into a PDF format using the application, rasterizing the map to a pixel format. The resulting drawing guarantees that each printout is without loss in the drawing part and content of the map. Unfortunately, the raster is not scalable, which means that the printout is only possible in one, previously assumed, scale. The map, reduced to A4 format, was added to the article on the final page.

\section{Summary and conclusions}

The article presents the stages of map creation and editing based on approximately 21 thousand measurement points measured by the GNSS method. The objective assumed at the beginning of the work was achieved.

The map editing required a special approach to the development and good knowledge of morphologically complex terrain. The key documentation were field notes and documentary photographs taken by the expedition's participants. The notes, together with terrestrial and satellite imagery available on the Norwegian website [19] provided a faultless multiple interpretation of the location of the structures on the very complex surface of the moraine.

An important step in the editing of the map was the development of the digital terrain model. The DTM was developed in two stages to eliminate outlying points. The first of the cloud points allowed to eliminate a part of points. The control of the course of contour lines, allowed the elimination of consecutive points with the wrong height coordinate. The rest of the points was the basis for the development of the final DTM. The contour lines were developed from the created model, whose course required manual correction.

For enhanced map readability, the automatically generated height features of the contour lines were enlarged and moved to the correct location. During map editing, attention should be paid to the generated objects as they may adversely affect map readability.

After the correct presentation of the moraine on the plane, the drawing was given the form of a map. Grids of geographic and kilometer coordinates were added. The last stage of the study was an outside the frame descriptions constituting the source of information about the map.

The map developed is a source of knowledge about the layout of the terminal moraine. Comparing the map developed in 2015 with previous cartographic studies, one can see how many processes and changes took place in the selected area. Map "Terminal moraine Werenskiold glacier. South-West Spitsbergen" is another Polish cartographic compilation, which fits into the canon of the maps of Hornsund. The map developed is the result of measurement work conducted within the III Polar Expedition of Wroclaw University of Technology in 2015 and financed from a statutory order S50051 at the Faculty of Geoengineering, Mining and Geology, Wroclaw University of Technology.

The study was carried out thanks to statutory order No. S50067 and Grant no. 0401/0128/17.

\section{References}

1. Z. Zwoliński, A. Kostrzewski, Polish geomorphological research on Spitsbergen, Z. Zwoliński, A. Kostrzewski, M. Pulina (eds.), Ancient and modern geoecosystems of Spitsbergen (Bogucki Wydawnictwo Naukowe, Poznań, 2013) 
2. W.T.J. Stankowski, S. Bartoszewski, K. Birkenmajer, J. Borsiak, E. Bukowska-Jania, A. Karczewski, S. Skiba, Z. Zwoliński, Geographical environment of Spitsbergen. Introduction, Z. Zwoliński, A. Kostrzewski, M. Pulina (eds.), Ancient and modern geoecosystems of Spitsbergen (Bogucki Wydawnictwo Naukowe, Poznań, 2013)

3. E. Bukowska-Jania, Glaciological Workshops, Spitsbergen 2004, Glaciology, geomorphology and sedimentology of the Spitsbergen polar environment, 100-103 (2004)

4. L. Kolondra, Werenskioldbreen and surrounding areas, Spitsbergen- orthophotomap 1:25 000. University of Silesia, Norsk Polarinstitutt-Tromso, Sosnowiec (2002)

5. W. Dallmann, W. (ed.) Geoscience Atlas of Svalbard, Tromso: Norsk Polarinstitutt (2014)

6. J. Hagen, O. Liestol, E. Roland, T. Jorgensen, Glacier Atlas of Svalbard and Jan Mayen, Oslo: Norsk Polarinstitutt (1993)

7. NASA, National Aeronautics and Space Agency website, http://eoimages.gsfc.nasa.gov/images/imagerecords/86000/86468/widesvalbard_amo_2 015213_lrg.jpg, access: 23.12.2015

8. TopoSvalbard, http://toposvalbard.npolar.no/, access: 23.12.2015

9. L. Kolondra, Geoinformatica Polonica, 7, 45-73 (2005)

10. Canadian Geographics: https://www.canadiangeographic.ca/article/10-fascinatinghistoric-maps-arctic access: 23.12.2015

11. M. Błaszczyk, Archiwum Fotogrametrii, Kartografii i Teledetekcji, 7, 53-62 (2007)

12. Norwegian Polar Instytute http://www.npolar.no/en/services/maps/interactive/,access: 21.12.2015

13. L. Kolondra, Mapy Svalbardu [In:] Z. Zwoliński, A. Kostrzewski, M. Pulina (eds.), Ancient and modern geoecosystems of Spitsbergen, Bogucki Wydawnictwo Naukowe, Poznań, 427-456 (2013)

14. E. Sobczyński, www.geoforum.pl, access: 23.12.2015 (2014)

15. T. Naumienko, Werenskiold glacier 1: 5000 - terminal zone. Military Topographic Service, Warsaw (1961)

16. J. Szupryczyński, Geographical works of the Institute of Geography of the Polish AcaDTMy of Science, No. 39, 56-92 (1963)

17. L. Kolondra, Polish Polar Studies, 28th International Polar Symposium, Poznań, 173186 (2002)

18. Research In Svalbard Database, https://www.researchinsvalbard.no/project/7644, access: 22.12.2015

19. The Nothern Lights Route, http://www.ub.uit.no/northernlights/eng/index.htm, access: 23.12.2015 
Teminal moraine - Werenskioldbreen glacier

South-Wost Spitsbergen

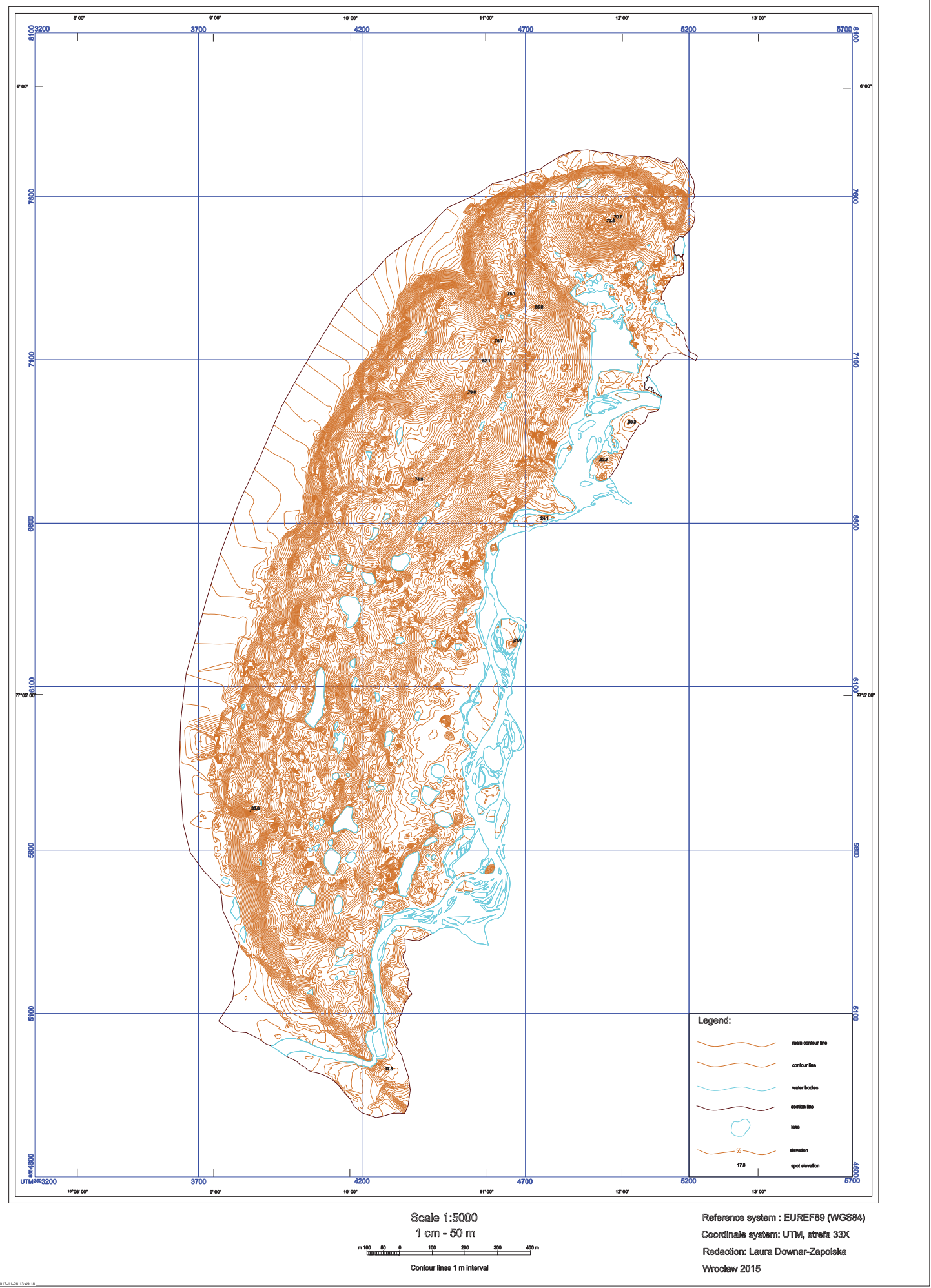

